\title{
Reflexões Sobre a Noção de Objetividade nas Ciências e na Matemática
}

\author{
Fabiana Chagas de Andrade \\ Centro Federal de Educação Tecnológica Celso Suckow da Fonseca (CEFET-RJ) \\ fabiana.andrade@cefet-rj.br
}

\begin{abstract}
Resumo
Neste ensaio teórico tecem-se algumas considerações sobre a noção de objetividade na ciência, de acordo com o atual significado do termo atribuído a Kant, a partir de algumas ideias da história, da psicologia e da sociologia da ciência à luz do referencial teórico de Fleck (2010), Bloor (2009), Latour e Woolgar (1997) e Daston (1999). Desde a década de 20, quando a concepção dominante adivinha das ideias defendidas pelo Círculo de Viena, a epistemologia da ciência vem sendo analisada por vários teóricos. A principal mudança nessa concepção foi a importância atribuída a fatores sociais e culturais no desenvolvimento da ciência e em um de seus aspectos, que faço uma breve análise: a objetividade. Explico a origem do termo e a mudança de significado a partir de Kant para, em seguida, construir uma breve abordagem histórica e, enfim, analisar as características da objetividade e seu papel na ciência. Por fim, busco compreender seu papel especificamente na matemática e entendo que ela nem sempre implica em uma verdade, que há possibilidade de existência de outras matemáticas e que a noção de subjetividade é também um componente na construção do conhecimento matemático. Tal estudo pode contribuir para repensar a forma como a matemática ainda é ensinada nas escolas.
\end{abstract}

Palavras-chave: Objetividade. Epistemologia da Ciência. Sociologia da Matemática.

\section{Thinking About the Notion of Objectivity in Science and Mathematics}

\begin{abstract}
In this theoretical essay, I make some considerations about the notion of objectivity in science, according to the current meaning of the term attributed to Kant, using some ideas of history, psychology and sociology of science in the terms of Fleck's theoretical reference (2010), Bloor (2009), Latour \& Woolgar (1997) and Daston (1999). Since the twenties, when the dominant conception came of the ideas defended by the Vienna Circle, several theorists have analyzed the epistemology of science. The main change in this conception was the importance attributed to social and cultural factors in science and in one of its aspects, which I intend to make a brief analysis: objectivity. I shall begin by explaining the origin of the term and the change of meaning since Kant. Next, I will make a brief historical approach to analyze the characteristics of objectivity and its notion in science. Finally, I try to understand objectivity specifically in mathematics and I understand that it does not always imply a truth, that there is a possibility of other mathematics, and
\end{abstract}


that the notion of subjectivity is also a component in the construction of mathematical knowledge. Such a study may contribute to rethinking how mathematics is still taught in schools.

Keywords: Objectivity. Epistemology of Science. Sociology os Mathematics.

\section{Introdução}

Antes de iniciar minhas reflexões sobre a noção de objetividade, cabe discutir o conceito de verdade científica, objetivo pelo qual a mesma perpassa e que, em geral, é buscado pelos cientistas. Para Bicudo e Garnica (2011), no século XIX, os questionamentos à então vigente visão da Ciência, a positivista, possibilitaram debates a partir de ideias sobre linguagem, cultura e história, que foram se fortalecendo ao longo do tempo e que conduziram modificações no entendimento das Ciências e, consequentemente, da realidade e conhecimento. Mas deixe-me voltar alguns passos para compreender o conceito de verdade que antecedeu tais modificações.

Existe, de fato, a verdade em um fato científico? Já no século VI a.C., Platão nos dava pistas com suas metáforas presentes no texto "O mito da caverna". Para ele, a verdade habitaria o mundo das ideias, um mundo perfeito e intocável, diferente do mundo em que vivemos. Assim, ela estaria posta e somente a alma poderia alcançá-la. A partir dessa visão, a verdade da matemática seria algo imutável e pré-existente, cabendo aos seres humanos apenas descobri-la a partir de seu esforço.

Com o desenvolvimento do saber científico, algumas maneiras de se chegar à verdade vieram à tona: as demonstrações, no caso da matemática (GARDIES, 1999) e os experimentos, no caso da física (FRANKLIN, 1999). Enquanto uma se constrói a partir de axiomas e estruturas de argumentação, a outra se utiliza de modelos físicos para simular o que ocorre, de fato, na natureza. Até mesmo a própria ideia de modelo é diferente nas duas ciências, porém não é escopo deste artigo discuti-la.

A partir das ideias de Fleck (2010), em seu livro "A construção de um fato científico", rompe-se a lógica positivista. À época da primeira edição - 1935 - o médico evidenciou como o fator social é determinante na construção do conhecimento científico. De acordo com esse entendimento, compreendo que a verdade é algo contextual, resultado de um estilo de pensamento compartilhado por uma comunidade de cientistas. É fato que essa verdade perpassa pelo crivo dos experimentos, demonstrações e argumentações de acordo com a Ciência envolvida e também passa pela divulgação científica e a aceitação por uma comunidade maior de cientistas.

Assim, neste texto admito que existem verdades que são provisórias, situadas em seu contexto político, histórico, social e cultural, resultados da produção humana. Um exemplo desse 
fato foi a contestação do quinto postulado de Euclides, que deu "origem" a outras Geometrias. A Geometria Euclidiana, que antes era vista como única verdade a partir de seus axiomas, ao ser questionada, possibilitou a ampliação do campo com as Geometrias não-Euclidianas.

Aceitando o componente social na obtenção de uma verdade, entendo que uma das preocupações dos cientistas é com a objetividade na construção de um fato científico. Ela foi tradicionalmente entendida como um aspecto de fundamental importância na produção dos estudos científicos e, a princípio, a subjetividade seria seu contraponto. Assim, minha motivação para construção deste ensaio foi: como refletir sobre a objetividade compreendendo a matemática como uma ciência construída socialmente? Qual noção de objetividade podemos ter para as ciências em geral e como ela foi contextualizada para a Matemática? A partir dessa noção, que implicações podem ser trazidas para o campo da Educação Matemática?

Para responder esses questionamentos, busco compreender como a noção de objetividade era entendida pelos filósofos escolásticos, qual é sua noção atual e como se desenvolveu, a partir de alguns autores como Bloor (2009), Daston (1999) e Latour e Woolgar (1997). Em seguida, construo algumas reflexões sobre seu papel nas Ciências e, em específico, na Matemática. A partir dessa discussão, teço algumas articulações com a Educação Matemática. Vale ressaltar que apresento um recorte a partir da visão de alguns autores, mas tenho ciência de que essa discussão que tem início na filosofia grega (como apresento nessa introdução) tem sido objeto de reformulações, novas contextualizações e tem marcado diferenças de posições e concepções no campo da ciência a partir de diferentes autores.

\section{Origem e significado do termo objetividade: uma visão histórica}

Segundo Daston (1999), o termo objetividade remonta aos filósofos escolásticos ${ }^{1}$ do século XIV e era dominante nas universidades medievais. Tais filósofos tinham inspiração nas ideias de Platão e Aristóteles e conciliavam a fé cristã e a racionalidade. Para eles, a objetividade tinha um significado quase oposto ao atual: referia-se às coisas como elas se apresentam à consciência, enquanto que subjetividade se referia às coisas em si. A partir da década de 20 do século XIX, $\operatorname{Kant}^{2}$ (1724-1804) deu novo significado ao termo: "relação a um objeto exterior", enquanto que a subjetividade era algo "pessoal, interno, que nos é iminente, por oposição a objetivo".

\footnotetext{
${ }^{1}$ A Escolástica foi uma filosofia de origem europeia que se iniciou no século IX e permaneceu até o início da Renascimento, no século XVI. Era inspirada nos ideais dos filósofos gregos Aristóteles e Platão, além de ter uma fundamentação cristã.

${ }^{2}$ Foi um filósofo prussiano considerado como o principal da era moderna. Operou, na epistemologia, uma síntese entre o racionalismo continental e a tradição empírica inglesa. No campo da filosofia, Kant apresentou a objetividade como algo que tem validade universal, independentemente de religião, cultura, época ou lugar.
} 
Na década de 20 do século passado, no Círculo de Viena ${ }^{3}$ reinava o neopositivismo, segundo o qual era preciso retomar o ideal clássico e partir da base empírica para se construir uma teoria do conhecimento. Aquilo que não podia ser verificado experimentalmente era considerado desprovido de sentido e para uma teoria ser considerada "ciência", ela deveria ser unificada em linguagem e fatos que a fundamentassem. Nesse contexto, o papel da Filosofia seria o de interpretar as proposições científicas, buscando sempre um ideal de objetividade.

A partir desse contexto, a busca pela objetividade tomou papel de grande importância da ciência, junto às outras virtudes como a verdade e rigor. Apesar de ser um termo complexo, todas as noções de objetividade tinham em comum uma proibição de algum aspecto do "eu", ou seja, objetividade e subjetividade pareciam ser eventos mutuamente excludentes, ou dois lados da mesma moeda dos fatos científicos. Fleck (2010) teve contato com essas ideias e foi o primeiro a considerar o fator social na construção de um fato científico, cunhando os termos "estilo de pensamento" e “coletivo de pensamento" em seu livro que só teve repercussão quase meio século após seu lançamento.

Podemos verificar, com base em Daston (1999), que a história da objetividade na Ciência a partir do ponto de vista destacado anteriormente é recente, pois sua preocupação com esse aspecto parece nascer do medo de que o "eu" possa interferir nas investigações científicas, modificando os fatos e ameaçando o conhecimento. Fleck (2010) faz referência à falta de verdade ocasionada pela interferência do "eu", quando menciona os desenhos dos aparelhos genitais feminino e masculino feitos por fisiologistas em um livro da época, que eram muitas vezes embelezados e fortemente influenciados por concepções sociais, levando inclusive a erros nas ilustrações.

\section{A noção de objetividade como um dos aspectos da Ciência}

Agora que sabemos um pouco da história do construto objetividade, podemos vê-la como um mal ou um bem necessário da Ciência? Digo mal ou bem, pois ela é apenas uma das qualidades da ciência, dentre outras como rigor e verdade, mas ocupa um lugar tão dominante que pode se sobrepor a outros objetivos importantes que guiam uma investigação científica. Os meios poderiam dominar os fins? Nesse sentido, ela seria um mal necessário à ciência. No século XIX, a

\footnotetext{
${ }^{3}$ O Círculo de Viena surgiu por uma necessidade de fundamentar a ciência a partir das concepções ou acepções que a Filosofia da Ciência ganhou no século XIX. Até então, a filosofia era vinculada à Teoria do Conhecimento. Era composto por cientistas que, apesar de atuarem em várias áreas como física, economia, etc., buscaram resolver problemas de fundamento da ciência, problemas estes levantados a partir de discussões com os neokantianos (seguidores de Kant) e os fenomenólogos (seguidores de Hegel).
} 
objetividade tinha status normativo e censurava qualquer traço de subjetividade. Seus ideais morais governavam as práticas e também a lealdade a elas.

Daston (1999) menciona um caso no qual, em nome da objetividade, cientistas do mundo todo empenhados em construir um mapa do céu (Carte $d u$ Ciel) utilizaram um equipamento menos preciso, porém mais fácil de operar e mais rápido, ao invés do mais avançado para a época. Nesse caso, a objetividade no sentido de criar uma uniformidade de observações - a objetividade comunitária - ultrapassou o objetivo da precisão, da verdade. Realizar essa tarefa seria impossível por um observador local; logo, foram realizadas escolhas por conta das circunstâncias da época, que envolveram consequências como o quê continuar investigando, quais instrumentos utilizar, como analisar os dados, etc. Essas escolhas foram feitas por cientistas que pertenciam a uma comunidade e compartilhavam um estilo de pensamento dentro de um coletivo de pensamento, nos termos de Fleck (2010), e, por isso, estavam imersos em um contexto cultural e histórico também específico.

A autora pontua que há dois tipos de objetividade: a comunitária, exemplificada anteriormente, e a mecânica, pois, segundo ela, o que é objetivo se opõe a algum aspecto do subjetivo (sensorial, cognitivo, emocional), mas nem sempre o mesmo. A objetividade mecânica se opõe às percepções sensoriais humanas, substituindo-as por instrumentos, como o caso da fotografia, que no século XIX acreditava-se suprimir a interferência do "eu", mesmo que a captura em preto e branco não representasse a verdade.

Nos dias atuais, a que a fotografia é uma arte subjetiva dentro dos referenciais teóricos que estamos adotando, à medida que a sensibilidade do fotógrafo interfere diretamente na luz, na cor, no ângulo e pode "ocultar" uma verdade ou mostrar uma inverdade. Um belo exemplo de que objetividade é diferente de verdade. Nessa modalidade de objetividade, a preocupação é a busca de um exemplar que represente um padrão para a totalidade, ou seja, uma busca pelo rigor, mas tal fato exigia uma interferência ativa na seleção e construção dos objetos, que estava fortemente influenciada pelo cientista. Por isso, também havia interferência do "eu" nesse processo.

A Ciência tinha preocupações distintas com o "eu" em cada um dos tipos de objetividade. Na mecânica, a preocupação era de a intervenção humana distorcer a natureza e na comunitária, de as escalas de tempo e espaço não registrarem de forma uniforme um fenômeno. Uma impunha um autocontrole de juízo e interpretação e a outra, a restrição da autonomia na escolha de instrumentos e métodos.

Observe que nos dois tipos de objetividade citados por Daston (1999) a subjetividade está presente. A objetividade mecânica não eliminou juízo e interpretação, e a comunitária não impediu competição entre grupos de investigação. Seria possível então, na construção de um fato científico, atingir a objetividade no sentido de oposição ao subjetivo? Seria possível deixar a natureza falar 
sobre si mesma, sem interferências? Podemos falar em níveis de objetividade, como níveis de confiança sobre um fato? Latour e Woolgar (1997) questionavam: como a objetividade que não tinha a sociedade por origem era produzida por essa sociedade? Como o objeto chegaria ao coletivo?

\section{A objetividade na construção de um fato científico}

Latour e Woolgar (1997) realizaram em 1988 uma etnografia de um laboratório, fato inédito para sociologia da época, que normalmente se ocupava de tribos que habitavam lugares remotos e minorias. Após dois anos de observações de integrantes desse laboratório, os autores concluíram que na construção de um fato científico o fator social é muito forte, apesar de os cientistas não se darem conta disso. Essa semente tinha sido plantada por Fleck, ainda em 1935, mas, por fatores adversos, sua obra ficou longo tempo esquecida, até ser redescoberta e amplamente discutida.

No laboratório estudado, as substâncias produzidas iam-se tornando fatos científicos em um processo gradual, à medida que os enunciados dos artigos científicos produzidos a partir das experiências iam sendo transformados pelos cientistas. A discussão entre pesquisadores dentro do laboratório transformava alguns dos enunciados em puros produtos da imaginação de uma subjetividade individual e estes eram silenciados; já outros eram transformados em fatos da natureza. Tal fato reforça a ideia de níveis de objetividade e do "eu" interferindo no que poderia tornar-se objetivo. Nesse contexto, o laboratório seria uma fábrica de fatos construídos em um movimento dialético e que, depois de constituídos, integravam um estoque de verdades científicas em as etapas e o contexto de sua gênese eram apagadas e esquecidas.

A partir dessas ideias, em minha leitura, seria inviável uma noção de cem por cento de objetividade em uma investigação, na visão dicotômica de Kant. Os fatos são construídos socialmente, em maior ou menor escala. Mas é inegável a interferência do subjetivo. As palavras objetivo e subjetivo não seriam mutuamente excludentes, mas podem-se tornar uma amálgama em que há mais o primeiro ou o segundo ingrediente.

Mas o fato de Latour e Woolgar (1997) terem observado um laboratório repleto de experiências acontecendo poderia enviesar a ideia do fator social interferindo na construção de um fato? Seria assim com todas as Ciências? A matemática seria um caso à parte? Para responder a essa pergunta, tomo a obra de Bloor (2009), que dedicou parte de seu livro a um olhar para a matemática. 


\section{A objetividade na Matemática e articulações com a Educação Matemática}

A matemática é uma ciência peculiar, pois não é dotada de experimentos. Os fatos e verdades matemáticas parecem ser independentes da interferência humana e, além disso, serem universais. Segundo Bicudo e Garnica (2011), a concepção absolutista tem resistido ao longo do tempo, mesmo com modificações no desenvolvimento da matemática, pela constatação da durabilidade e suposta objetividade dos objetos matemáticos.

Essa perspectiva reforça a ideia de uma matemática para poucos e privilegiados, a separação no meio escolar entre alunos bons e ruins pelo seu desempenho na disciplina e o aumento da importância da mesma como instrumento de poder. A respeito dessa última ideia, recorremos ao que o autor Skovsmose (2007, p. 81) chama de Ideologia da Certeza: “[...] refere-se a um respeito exagerado pelos números. A ideologia afirma que a Matemática, mesmo quando for aplicada, apresentará soluções corretas asseguradas por suas certezas. A precisão da Matemática (pura) é como que transferida para a precisão das soluções aos problemas."

Apesar de termos diferentes culturas coexistindo no mundo, elas desenvolvem uma mesma matemática? A noção de verdade é muito forte e parece imune a fatores sociais. Seria possível, então, uma sociologia da matemática, em seu cerne? Seriam os objetos matemáticos dotados de objetividade? Bloor (2009) defende que a sociologia, em conjunto com a psicologia, pode fornecer uma abordagem adequada para explicar a natureza do conhecimento matemático. $\mathrm{O}$ componente psicológico proporcionaria os conteúdos das ideias e o sociológico buscaria modelos físicos e reforçaria sua autoridade.

Para defender suas ideias, o autor toma como exemplo o conceito de número, que não seria nem psicológico nem um objeto, mas o que ele chama objeto da razão. Esses objetos ${ }^{4}$ seriam $^{2}$ dotados de objetividade. Para Frege $^{5}$ (1959, apud BLOOR, 2009), a objetividade estaria independente das sensações e imagens mentais criadas a partir dela, mas não aquilo que é independente da razão. A razão interfere na leitura de mundo e é um componente teórico do conhecimento, porém social, ou seja, há interferência de algum aspecto do "eu" na matemática, se entendermos que a matemática é produzida por seres humanos. Assim, desde que não se esteja na concepção platônica da matemática, tem-se clareza de que os objetos matemáticos têm interferência do "eu". Eles são objetos criados, descobertos e investigados pelo homem. Portanto, nascem na subjetividade de seu criador, sustentam-se na intersubjetividade e são objetivados pela linguagem, ou seja, validados, comunicados, e, a partir disso, tornam-se objetos culturais.

\footnotetext{
${ }^{4}$ Um exemplo de objeto da razão seria a linha do Equador.

${ }^{5}$ FREGE, G. The foundations of Arithmetic (traduzido por J. L. Austin). Oxford: Blackwell, 1959.
} 
Já para Russell (1970), conforme Bicudo e Garnica (2011), os objetos matemáticos seriam “idealidades". Para o autor, eles são constituídos historicamente e se originam no ato da evidência original e subjetiva, ocorrido na esfera psicológica do sujeito, e que é comunicado com outros. A partir dessa noção, a linguagem também sustentaria os objetos, os transportando ao longo do tempo, mas passíveis de interpretações distintas. Aqui também se admite a subjetividade como componente das entidades matemáticas.

Assim, corroborando essa noção de objetividade, que permite a interferência humana racional, poderíamos afirmar que a matemática é objetiva? Admitido o componente social na objetividade, poderíamos falar então de matemáticas alternativas?

As diferenças na classificação dos números da matemática grega e a nossa podem indicar uma divergência no estilo cognitivo. No que se refere aos conjuntos numéricos, entende-se que a noção de número não teria passado por extensões ou ampliações, mas por uma mudança na “intenção" do número. Quando algebristas encontraram o trabalho de Diofanto ${ }^{6}$, que admitia apenas soluções positivas para equações, eles reinterpretaram-no segundo outro estilo de pensamento. O que para Diofanto seria impensável à época, era absolutamente possível segundo um outro estilo de pensamento. Mas por se tratarem de períodos diferentes, poderíamos assumir que isso seria um exemplo de matemática alternativa? A interpretação de número do passado, como resultado do processo de contagem, e hoje, como entidades abstratas, seria essa resposta?

Bloor (2009) lança mão de diversos outros exemplos para convencer o leitor de que mudanças no modo de conceber objetos matemáticos são, sim, consideradas matemáticas alternativas. Machado (2009) também ressalta que a representação simbólica para os números feita por Diofanto não era prática para o desenvolvimento do Cálculo, que era uma necessidade teórica que não se tornou social à época, e, por isso seu trabalho foi silenciado. Assim, historicamente, tal fato mostra que matemáticas alternativas têm sido silenciadas.

Se pensarmos na matemática alternativa como uma ciência com diferentes estilos de pensamento oriundos de diferentes comunidades de matemáticos, assim como ocorre em outras comunidades de cientistas, a resposta seria que a matemática é objetiva e admite a existência de matemáticas. Mas a matemática é diferente, ou o nosso pensamento acerca dela é diferente?

Pensemos na etnomatemática ${ }^{7}$, que considera e valida modos diferentes de fazer matemática em grupos sociais específicos. Se admitirmos a perspectiva de Bloor (2009) de que a matemática é uma construção social, fazer matemática de maneira diferente constituiria uma

\footnotetext{
${ }^{6}$ Matemático grego, considerado o pai da Álgebra. Viveu por volta do século III a.C.

${ }^{7}$ Etnomatemática é o reconhecimento de que as ideias matemáticas são próprias da natureza humana. Assim, a Matemática é "espontânea, própria do indivíduo" e moldada pelo "meio ambiente natural, social e cultural em que este se insere. (VIEIRA, 2008, P.163)
} 
matemática alternativa. Assim, poderíamos pensar em matemáticas alternativas sob duas perspectivas: a de diferentes estilos de pensamentos das comunidades de matemáticos e a de diferentes práticas matemáticas que ocorrem dentro de culturas específicas. A diferença entre elas é que a primeira constitui o saber esotérico e a segunda o exotérico, mas ambas são uma construção social e coletiva.

Para situar o leitor, cabe esclarecer que o conhecimento exotérico é o que diz respeito ao mundo dos fenômenos. É o conhecimento do mundo e das leis do universo, que podem ser percebidas pelos sentidos, como a gravidade. Por outro lado, o conhecimento que não pode ser descrito em termos de fenômenos físicos e nem percebido pelos sentidos, é classificado como conhecimento esotérico. É adquirido pelos processos da razão e a associação de ideias.

Podemos perceber também que os tipos de objetividades citados por Daston (1999) podem ser vistos na matemática. A objetividade mecânica, representada pela fotografia, pode ser entendida na matemática quando utilizamos instrumentos que agilizam a velocidade dos cálculos e reduzem o erro humano, como os computadores, calculadoras, etc. Cabe aqui lembrar que as últimas podem ser programadas de modo a não respeitar certas propriedades matemáticas que, em certas circunstâncias, podem levar a respostas incorretas. Assim, a objetividade não seria sinônimo de verdade também nesta ciência.

A objetividade comunitária e sua uniformidade é algo bem alcançado na linguagem matemática universal. Mas os objetos matemáticos podem receber diferentes roupagens de acordo com a finalidade e o campo matemático como os Números Reais, que podem ter uma representação algébrica, geométrica ou figural, à medida que os matemáticos os utilizam em diferentes situações. Logo, não é a forma de expressão do objeto matemático que o considere (ou não) objetivo. Os objetos matemáticos são objetivos, mas o rigor dos signos pode apresentá-los de diferentes maneiras.

Mais quais implicações a noção de objetividade na Matemática pode trazer para o contexto da Educação Matemática? A visão do componente subjetivo na objetividade está de acordo com o grupo de educadores matemáticos que veem a matemática como uma construção social, e, por isso, poderíamos falar em uma cultura matemática, ao invés de uma matemática segundo Platão, que está na natureza e deve ser "descoberta".

Com isso, se admite a importância e a validade de outras matemáticas, que podem dar mais sentido à aprendizagem dos alunos, levando em consideração seu contexto social e cultural. Um exemplo desse fato é o trabalho com artefatos africanos em Geometria, ou o uso de métodos de cálculo utilizado por indígenas nas aulas de matemática. O professor que faz valer essa premissa admite a importância do social na aprendizagem do aluno, valoriza suas práticas matemáticas e 
democratiza o ensino de matemática, na verdadeira perspectiva da matemática para todos, e não da matemática "para quem".

Por outro lado, também percebo que uma perspectiva muito difundida é a de neutralidade, precisão, rigor e objetividade na Matemática (MACHADO, 2009). Assim, mudar essa visão pode possibilitar o questionamento das finalidades e dos usos da matemática, que é uma das perspectivas da Educação Matemática Crítica (SKOVSMOSE, 2007). Nela, o ensino é trabalhado por meio de investigações, os cenários de investigação, e questões abertas. Tal perspectiva enfraquece a ideologia da certeza e vai de encontro à visão absolutista da matemática, que contribui para perpetuar o fato de que ela é a "Rainha das Ciências". Alguns trabalhos no ensino com a Modelagem Matemática têm adotado essa perspectiva.

\section{Para Concluir?}

Finalizo este texto com a ideia de que a noção de objetividade foi construída e modificada em sua história e pode se comportar de diferentes maneiras em diferentes ciências. Corroboro a visão de Daston (1999), mas acredito que a ideia de Frege (1959) de incluir um componente social na noção de objetividade resolve muitas divergências acerca do termo. Apesar de a subjetividade ser aceita teoricamente como um componente da objetividade nos textos, na prática, o discurso ainda resiste na ideia dicotômica entre estre esses termos, tanto entre matemáticos como entre educadores matemáticos.

Acredito que aceitar a interferência do "eu" racional, visto que os fatos científicos ou objetos matemáticos são produzidos dentro da sociedade, e que seria impossível "esterilizá-los" da interferência humana, seria inteligente. E mais do que isso, poderíamos falar sobre o componente social estar mais ou menos forte dentro dos tipos de objetividade, mecânica e comunitária, funcionando como níveis em uma "moral" das Ciências. O problema não seria a interferência humana, mas uma interferência sem espírito científico, sem raciocínio sistematizado. Assim, a subjetividade não é um mal para a ciência, nem para as matemáticas. Seria um bom caminho para se pensar nesse construto.

Por fim, refletir sobre essas questões pode contribuir para enfraquecer a visão absolutista que ainda pode perdurar nas mentes dos professores, que separa os alunos bons dos ruins, que acredita em respostas corretas, que trabalha com questões fechadas e que desconecta o contexto social do aluno, podendo desqualificá-lo, ao não considerar matemáticas alternativas. Para mim, a partir dessas reflexões e do que a literatura mostrou, admitir que a objetividade tem um componente 
subjetivo também na matemática, nos auxilia a compreendê-la como uma construção social, que tem profundas interferências da história, do social e da cultura.

\section{Referências}

BICUDO, M. A. V.; GARNICA, A. V. M. Filosofia da Educação Matemática. Autêntica, 2011. BLOOR, D. Conhecimento e imaginário social. Trad. Marcelo do Amaral Penna-Forte. São Paulo: Editora Unesp. 1 ed.,1976. 2009.

DASTON, L. As imagens da objetividade: a fotografia e o mapa. Ed. GIL, Fernando. A ciência tal qual se faz. Lisboa: Sá da Costa, 1999.

FLECK, L. Gênese e desenvolvimento de um fato científico. Trad. Georg Otte e Mariana Camilo de Oliveira. Belo Horizonte: Fabrefactum. 1.ed., 1935. 2010.

FRANKLIN, A. Os papeis da experiência. In: A ciência tal qual se faz. Ed. GIL, Fernando. 305327. Porto: João Sá da Costa Lisboa, 1999.

FREGE, G. The foundations of Arithmetic. (traduzido por J. L. Austin). Oxford: Blackwell, 1959.

GARDIES, J. Demonstração e verdade. In: A ciência tal qual se faz. Ed. GIL, Fernando. 287304. Porto: João Sá da Costa Lisboa, 1999.

LATOUR, B.; WOOLGAR, S. A vida de laboratório: a produção dos fatos científicos. Trad. Angela R. Vianna. Rio de Janeiro: Relume Dumará. 1ed. 1988. 1997

MACHADO, N. J. Matemática e realidade. São Paulo: Cortez, 2009.

VIEIRA, N. Para uma abordagem multicultural: o Programa Etnomatemática. Revista Lusófona de Educação, Lisboa, n.11, p.163-168, 2008. Disponível em <https://bit.ly/2QAbI2E>. Acesso em 10. Mar. 2018.

SKOVSMOSE, O. Educação Crítica. Incerteza, Matemática, Responsabilidade. Trad. M. A. V Bicudo. São Paulo: Cortez, 2007. 